\title{
OS DIÁLOGOS NA CONSTRUÇÃO DE TEXTOS E DISCURSOS DE "CARA-DE-BRONZE", DE JOÃO GUIMARÃES ROSA: DIMENSÃO POÉTICA E CENTROS DE VALOR
}

\author{
DIALOGUES IN THE CONSTRUCTION OF TEXTS \\ AND DISCOURSES IN "CARA-DE-BRONZE", BY JOÃO \\ GUIMARÃES ROSA: POETIC DIMENSION AND CENTERS OF \\ VALUE
}

José Geraldo MARQUES'

Resumo: Neste artigo, faço uma reflexão sobre a importância dos diálogos na construção de textos e discursos da novela "Cara-de-Bronze", presente no volume No Urubuquaquá, no Pinhém, de João Guimarães Rosa. Discutirei também o estatuto da dimensão poética da obra em que o deslocamento e a convergência de seus centros de valor para um único centro de valor - o poético - mostram-se centrais para sua arquitetônica.

Palavras-chave: Alteridade. Arquitetônica. Dialogia/Diálogo. Exotopia. TextoEnunciado.
ABSTRACT: In this article, I reflect on the importance of dialogues in the construction of texts and discourses of the novel "Cara-de-Bronze", which is part of the volume "No Urubuquaquá, no Pinhém", by João Guimarães Rosa. I will also discuss the statute of the poetic dimension of the work, in which the displacement and convergence of its centers of value to a single value center - the poetic - reveals themselves as central to its architectonics.

Keywords: Alterity. Architectonics. Dialogism/Dialogue. Exotopy. TextEnunciation. 
- Os diálogos na construção de textos e discursos de "Cara-de-bronze", de João Guimarães Rosa: dimensão poética e centros de valor

\section{Introdução}

Neste artigo, proponho refletir, do ponto de vista da Análise Dialógica do Discurso (ADD), sobre a importância dos diálogos na construção dos textos e discursos de "Carade-Bronze", novela de João Guimarães Rosa presente em No Urubuquaquá, no Pinhém, um dos volumes que compõem a obra Corpo de Baile.

Sabemos por meio de diversos textos de Bakhtin e do Círculo que dialogia e diálogo são "coisas" diferentes ou, para ser mais preciso, a dialogia, princípio constitutivo de toda e qualquer linguagem, pressupõe o diálogo. Mas isso não traz nada de concreto. A pergunta mais precisa, acredito, seria a seguinte: o que importa em relação à forma composicional secundária que foi cristalizada na história da cultura ocidental como "diálogo"?

Bakhtin e os demais intelectuais que compuseram o que hoje conhecemos como o "Círculo de Bakhtin" não se interessavam pelo diálogo enquanto estrutura composicional (conversa de personagens e turnos de personagens em um texto dramático ou "o desenrolar da conversação na interação face a face"), mas com aquilo que ocorre "com o complexo de forças que nele atua e condiciona a forma e as significações do que é dito ali" (FARACO, 2017, p. 60-61).

Faraco se refere a conversas face a face, mas, de uma perspectiva bakhtiniana, acredito que isso é perfeitamente legítimo para um objeto estético específico, se entendemos que "de fato, a vida não se encontra só fora da arte, mas também nela, no seu interior, em toda plenitude de seu peso axiológico: social, político, cognitivo ou outro que seja" (BAKHTIN, 1993, p. 33).

Em síntese, o fundamental para o meu trabalho sobre os diálogos em "Cara-deBronze" são as forças que neles atuam, condicionando as formas e as significações do que se diz ali. E o que seriam essas forças que atuam nos diálogos? É evidente que elas, na vida concreta, são consequência do "entrecruzamento das múltiplas verdades sociais [...], isto é, a confrontação das mais diferentes refrações sociais expressas em enunciados de qualquer tipo e tamanho postos em relação" (FARACO, 2017, p. 62). E a essas verdades sociais, axiologicamente transfiguradas pelo objeto estético, soma-se também a estrutura arquitetônica da obra que, simplificadamente, poderia ser entendida como as relações estabelecidas entre autor-criador, o herói e o leitor a partir de "um colocar-se de fora" (exotopia) do autor-criador.

A dimensão poética, bastante intensa nessa novela de Rosa, servirá de base para minhas reflexões. Ela tem sido atestada por muitos dos estudos dedicados a "Cara-de- 
Bronze", que, não obstante, não foram capazes de elucidar o peso dessa exigência, qual a natureza dela e muito menos qual sua função na arquitetônica deste texto singular. Refletir dialogicamente sobre a dimensão poética da obra e consequentemente sobre a insuficiência do que foi dito sobre ela será o objetivo central deste artigo. Atestar e defender a dimensão política dos diálogos escolhidos para análise será também ponto importante do trabalho. Não se trata de trazer algo extrínseco à literatura de Guimarães Rosa: na obra de todo grande autor, a dimensão política é algo sempre à espera de uma leitura que possa ressignificá-la.

Bakhtin (2016), em "O texto na linguística, na filologia e em outras ciências humanas", conjunto de anotações feitas, segundo Paulo Bezerra, entre 1959 e 1961, considera o texto, oral ou escrito, como o elemento fundante da Linguística, da Teoria Literária, da Filologia e outras disciplinas. Nesse artigo, ele define texto "no sentido amplo, como qualquer conjunto coerente de signos" (BRAIT, 2012, p. 11). E é nessa mesma obra que ele propõe o texto como enunciado, apresentando os dois elementos que o determinam como tal: "a sua ideia (intenção) e a realização dessa intenção" (BAKHTIN, 2016, p. 73).

Alguns estudiosos do pensamento bakhtiniano entendem, a meu ver, acertadamente, "intenção" como projeto de dizer e a "realização" desse projeto, $a$ relação dialógica de autores e interlocutores com outros textos-enunciados. Bakhtin (2016, p. 73) amplia essa ideia, afirmando que o texto como enunciado deve ser "incluído na comunicação discursiva (na cadeia textológica) de dado campo, (nas) relações dialógicas entre os textos e no interior de um texto".

Se há interação e se ela se dá, no mínimo, entre duas consciências, ao leitor ou ouvinte (interlocutor) interessa a construção dialógica de um discurso que se dá pela antecipação/compreensão da palavra do outro, pelo tema que se desenvolve na interação e principalmente pelos valores que estão sendo colocados em jogo. Voltando ao trabalho de Brait (2012), um texto é parte do todo de um enunciado completo. Ou seja: o textoenunciado proposto por Bakhtin, mais do que isso, concretiza uma relação fundamental entre texto e enunciado concreto. Nessa interpretação (ou estudo) do texto-enunciado, haverá necessariamente o encontro entre duas consciências.

Texto-enunciado, dialogia, arquitetônica e alteridade serão as principais categorias reflexivas bakhtinianas com as quais trabalharei neste artigo. É fundamental, entretanto, deixar claro que as ideias de Bakhtin e as do Círculo de pensadores do qual fez parte não são passíveis de operacionalização. As reflexões do chamado "Círculo de Bakhtin" não são aplicáveis no sentido da aplicação de conceitos que fariam parte de um universo intelectual restrito a uma ou mais teorias. Bakhtin é, antes de tudo, um descobridor, um 
- Os diálogos na construção de textos e discursos de "Cara-de-bronze", de João Guimarães Rosa: dimensão poética e centros de valor

pensador, um filósofo que conectou de maneira insolúvel a vida à arte, aos discursos, às esferas de onde estes emanam e à cultura.

Ao pesquisador e/ou estudioso de sua obra, dependendo do campo e do objeto escolhidos para reflexão, cabe delimitar algumas dessas categorias (as mais abertas dialogicamente aos seus objetivos) e iluminar o seu estudo através delas. Os resultados dependerão da competência dialógica na descoberta de alguns caminhos possíveis para viabilizar relações entre o objeto escolhido e o nosso tempo. Entretanto serão sempre dada a plasticidade, a fluidez e à própria dialogicidade intrínsecas às categorias analíticas bakhtinianas - resultados provisórios, moventes, inacabados, à espera de outros estudos que contemplem os mesmos objetos (ou que tenham afinidade com eles) a partir de outras leituras e que os ampliem.

\section{Diálogos, textos e discursos}

Os diálogos conformam cerca de $64 \%$ da massa verbal de "Cara-de-Bronze" e as intervenções do narrador, 23\%, aproximadamente apenas um terço dos diálogos². Tratase de diálogos entre os vaqueiros, com a participação, em alguns deles, de três forasteiros que foram comprar bois na fazenda de Segisberto Saturnino Jéia Velho, Filho, o nome completo do Cara-de-Bronze, proprietário da fazenda: linhô Ti, Seo Sintra e Moimeichêgo. Os temas dos diálogos giram em torno à curiosidade geral dos vaqueiros a respeito do patrão, o "Cara-de-Bronze", que se encontra, naquele momento, doente, praticamente em seu leito de morte, e à curiosidade em torno da viagem de dois anos que o Grivo, um de seus colegas, empreendeu até a Vereda do Sapal a mando do patrão. Esses diálogos, na arquitetônica da narrativa, servem de preparação, de subsídios e pressupostos para o grande momento da estória: o relato do Grivo sobre a sua viagem a mando de Segisberto Saturnino Jéia.

Como afirmei acima, as enunciações do narrador somam apenas um terço das enunciações dos diálogos de "Cara-de-Bronze". Isso não quer dizer que a presença do narrador seja algo desimportante no desenvolvimento do texto de Rosa: ela deixa igualmente pistas para a produção de sentidos de muitas leituras possíveis. No entanto, minha proposta se fixa nos diálogos, pois eles marcam concretamente a dialogia das trocas verbais entre os vaqueiros, personagens fundamentais da narrativa. Evocarei aqui também o narrador em sua "presença anômala" e isso se dá principalmente nos textos

\footnotetext{
2 Trata-se apenas de números aproximados, chamando a atenção para a importância capital dos diálogos na construção de "Cara-de-Bronze".
} 
em que "faz dueto" com o Grivo em um tipo de discurso indireto livre instável que não se materializa no texto como tal, mas que se manifesta estranhamente como algo exterior ao acontecimento narrado, "ocupando uma espécie de limbo entre o enunciado e a enunciação" (SANTIAGO, 2012, p. 53).

Os diálogos estão organizados em textos mais ou menos marcados na narrativa que, por sua vez, são atravessados por muitos discursos - os dos vaqueiros, de Moimeichêgo, os do Grivo e também aqueles do Cantador, neste caso, alguns presentes nas cenas enunciativas, outros não. A estrutura arquitetônica da narrativa é constituída pela relativa ignorância geral em relação ao patrão (como é fisicamente, qual é sua história, qual é sua concepção de mundo, por que mandou e o que pediu para o Grivo quando exigiu que ele fosse para o Sapal e além etc.) e em relação ao companheiro vaqueiro Grivo (o que trouxe de lá para o Cara-de-Bronze, o que trouxe para si (uma suposta noiva), por que ficou tanto tempo fora...), tudo isso convergindo para o núcleo da narrativa: o relato do Grivo.

Recortei, para este estudo, textos que conformam os diálogos da novela. Entre as páginas 96 e 99 (ROSA, 2016), os vaqueiros especulam se o Grivo, recém-chegado, disse alguma coisa da viagem, se contou alguma coisa a alguém sobre uma moça com quem teria se casado e trouxe para a fazenda, de que maneira foi, como voltou etc. Logo após a primeira fala de Moimeichêgo, muda-se de tema e a conversa gira em torno ao Cara-deBronze (ROSA, 2016). Quando o vaqueiro Adino questiona Moimeichêgo (ROSA, 2016, p. 102), afirmando que a curiosidade deste último lembrava-Ihe os "assuntos do Carade-Bronze", Moimeichêgo pergunta: Que assuntos dão esses? A partir daí, o essencial da viagem/busca do Grivo, começa a ser tematizado. É esse o primeiro texto escolhido para reflexão e ele vai dessa pergunta do forasteiro até a única fala do vaqueiro José Uéua antes da "Ladainha".

\section{Textos e discursos}

Texto - enunciado $\mathrm{n}^{\circ}$ 1. A viagem do grivo: quando os discursos dos vaqueiros vagueiam [p. 102 e 103]

O vaqueiro Adino: É engraçado... o que o senhor está dizendo, é engraçado: até, se duvidar, parece no entom desses assuntos do Cara-de-Bronze fazendo encomenda deles aos rapazes, ao Grivo...

Moimeichêgo: Que assuntos são esses?

O vaqueiro Adino: É dilatado p'ra se relatar... 
- Os diálogos na construção de textos e discursos de "Cara-de-bronze", de João Guimarães Rosa: dimensão poética e centros de valor

O vaqueiro Cicica: Mariposices... Assunto de remondiolas.

O vaqueiro José Uéua: Imaginamento. Toda qualidade de imaginamento, de alto a alto... Divertir na diferença similhante...

O vaqueiro Adino: Disla. Dislas disparates. Imaginamento em nulo-vejo. É vinte réis de canela em pó...

O vaqueiro Mainarte: Não senhor. É imaginamentos de sentimento. O que o senhor vê assim: de mansa mão. Toque de viola sem viola. Exemplo: um boi - o senhor não está enxergando o boi: escuta só o tanger do polaco dependurado no pescoço dele; - depois aquilo deu um silenciosim, dele, dele -: e o que é que o senhor vê? O que é que o senhor ouve? Dentro do coração do senhor tinha uma coisa lá dentro - dos enormes...

O vaqueiro José Uéua: No coração a gente tem é coisas igual ao que nem nunca em mão não se pode ter pertencente: as nuvens, as estrelas, as pessoas que já morreram, a beleza da cara das mulheres... A gente tem de ir é feito um burrinho que fareja as neblinas? [... $]^{3}$

Esse texto joga o leitor pela primeira vez em um registro que não o da linguagem que até então marcara os discursos dos vaqueiros, seja no referir-se ao Cara-de-Bronze, seja na tentativa de entender a viagem do Grivo, ou seja, um registro informal, porém marcado por uma linguagem de comunicação, informacional, pragmática, instrumental, sem nuances ou expressividade. Esse pequeno diálogo não nos joga diretamente na viagem do Grivo, mas nos discursos dos vaqueiros que aqui tematizam os assuntos tratados entre o patrão, "os rapazes, e o Grivo", assuntos que tinham como foco as exigências que o Cara-de-Bronze fez aos vaqueiros (a encomenda, na primeira enunciação de Adino).

Os discursos dos vaqueiros se dividem: as respostas de José Uéua e Mainarte à pergunta de Moimeichêgo se mostram favoráveis aos assuntos tratados entre o patrão e o Grivo (o escolhido); em oposto, as observações de Cicica e Adino são francamente negativas: para o primeiro, seriam "assuntos de remondiolas" e "mariposices". Rosa (1981, p. 66) explica, ao seu tradutor italiano, Edoardo Bizzarri, que "remondiolas" são "artes" [...], "traquinadas", "travessuras", "maluquices", "macaquices". "Mariposar" é "perderse em devaneios, devanear, fantasiar". Para Cicica, portanto, aqueles assuntos tratados principalmente com o Grivo pelo Cara-de-Bronze estariam sob os signos da fantasia e da loucura.

3 No subtítulo "A viagem do Grivo: quando os discursos dos vaqueiros vagueiam", a forma verbal "vaguear" não aparece no sentido de "vago", ou seja, de "impreciso", de "incerto", mas como "andar passeando por (lugares) sem rumo certo, ao acaso"; ou ainda, emulando novamente Rosa, "desandar", não no sentido de "perder consistência" ou simplesmente "perder-se" na vida ou na conduta, mas como negação dos caminhos retos, cartesianos, objetivos, ou seja, andar por outros caminhos, outras paragens - tortuosas, mais amplas, complexas - que os atalhos da lida e de sua linguagem, instrumental, direta, de ofício. 
Adino, em sua segunda enunciação, diz sobre os assuntos tratados entre o patrão e o Grivo: "Disla. Dislas disparates. Imaginamento em nulo-vejo. É vinte réis de canela em pó...". Ou seja: imaginação inútil, desperdício (ROSA, 2006, p. 102). "Disla”, retomada no início do próximo enunciado como plural, "Dislas", provavelmente redução de "dislalia", perturbação na articulação das palavras por lesão de algum dos órgãos fonadores. Os outros dois companheiros de Grivo nas primeiras viagens defendem os assuntos tratados pelas partes, justamente porque, como compartícipes delas, ouviram-nas e ouvindo-as puderam ponderar a respeito, julgá-las, compreendendo-as ${ }^{4}$, enfim.

José Uéua oferece uma contrapalavra à apreciação negativa de Cicica; Mainarte, à de Adino. Em relação aos argumentos de Cicica (fantasia e loucura), Uéua contrapõe: "Imaginamento. Toda qualidade de imaginamento, de alto a alto... Divertir na diferença similhante...", ou seja, para ele, trata-se de imaginação e não de loucura. E continua: "imaginamento de alto a alto" (ROSA, 2006, p. 102), feliz reconstrução da expressão de alto a baixo, supervalorizando o argumento da imaginação. E a surpreendente consideração de divertir na diferença semelhante, enunciado prenhe de sentidos diversos: a diferença semelhante, ou seja, diferença que se faz de nuances sutis, quase imperceptíveis (mas não iguais) e a possibilidade de se divertir dentro desse quadro de diferenças respeitadas, nem tão diferentes assim, mas um pouco semelhantes, sendo que essas semelhanças só seriam possíveis num contexto em que a palavra do outro fosse de fato ouvida e compusesse de algum modo (por relativização, modalização, discordância, concordância, assimilação etc.) uma possibilidade dialógica, de respeito à alteridade. E ainda a ideia da diversão, de alegria, de felicidade, resultante de uma interação que, embora não desconsidere a desigualdade socioeconômica dos interlocutores, reconhece uma compreensão, a possibilidade de um fazer em que a alegria seja dialogicamente triste e que a dificuldade de executar a tarefa seja, ao mesmo tempo, facilidade de fazê-la. Em síntese: a possibilidade de divertir-se com a diferença semelhante é a matéria mesma da imaginação, ou ainda, a imaginação é a possibilidade de se divertir (gozar, alegrar-se) no âmbito de diferenças em que alguns pontos se assemelham.

A contrapalavra de Mainarte ao vaqueiro Adino, para quem os imaginamentos de Uéua não passariam de disparates e Imaginamento em nulo-vejo, ou seja, imaginação sem fins racionais, que não tem os pés no chão, que não usa os olhos ("nulo-vejo") como possibilidade de crer ("ver para crer"), redefine e predica de outro modo a imaginação: "Não senhor. É imaginamentos de sentimento" (ROSA, 2006, p. 103). À imaginação como causa da alegria de divergir respeitando as alteridades, Mainarte acrescenta os

4 "Compreender" em sentido bakhtiniano, ou seja, oferecendo uma contrarresposta dialógica. 
- Os diálogos na construção de textos e discursos de "Cara-de-bronze", de João Guimarães Rosa: dimensão poética e centros de valor

sentimentos, ou seja, imaginação subordinada aos sentimentos, imaginação como produto central do sentimento. A contrapalavra de Mainarte coloca em xeque o argumento da imaginação irracional formulada por Adino: agora, a imaginação vem dos sentimentos, se origina neles e o elemento racional será aquela alegria advinda de um entendimento que, embora desigual e diferente (pois enunciados de lugares sociais díspares), opera por alguns de seus pontos de contato. Os exemplos para essa imaginação do sentimento que não desconsidera o outro em uma dialogia complexa e alegre são metáforas de uma sensibilidade extremamente sutil:

[...] O que o senhor vê assim: de mansa mão. Toque de viola sem viola. Exemplo: um boi - o senhor não está enxergando o boi: escuta só o tanger do polaco dependurado no pescoço dele; - depois aquilo deu um silenciosim, dele, dele -: e o que é que o senhor vê? O que é que o senhor ouve? Dentro do coração do senhor tinha uma coisa lá dentro - dos enormes... (ROSA, 2006, p. 103).

Essa mão, que é mansa, que tange a viola prescindindo dela... O boi, que não é enxergado (resposta ao ver para crer de Adino), mas permite ouvir o tilintar do polaco e que, no silêncio de um átimo, não ouve mais, confundindo o sujeito que o ouvia, desaquietando o seu coração... Ora, essas metáforas mostram que os ouvidos enxergam melhor que os olhos, pois pressupõem uma escuta, pressupõem o outro, a alteridade. A razão e os olhos, por outro lado, exigem causas, identificam-nas, dão etiquetas a elas (nomeiam-nas) e as empilham em classificações congeladas. O sentimento, a razão, a alegria e a escuta atenta advindos da compreensão marcam a complexidade de um mundo cujas relações (sobretudo linguísticas e discursivas) passam para muito além de uma razão cartesiana, instrumental e meramente comunicativa.

A coisa enorme do coração a que alude Mainarte conecta a subjetividade ao mundo: a sutileza de um sinal sonoro é metonímia de algo grande: o boi. Ele - o sinal - mostra que a subjetividade necessita do real, de seus objetos, de sua materialidade, para que possa se conectar a si mesma a partir do mundo. A última fala de José Uéua explica essa enormidade interior constitutivamente ligada ao real: "no coração cabem as nuvens, as estrelas, as pessoas que já morreram, a beleza da cara das mulheres... [...]". E a constatação em forma surpreendente de pergunta que anula qualquer certeza: "A gente tem de ir é feito um burrinho que fareja as neblinas? [...]" (ROSA, 2006, p. 103): sugestão, dúvida, compartilhamento do sensível - e nunca certeza, constatação, finalização. Essa belíssima imagem de que cabem em nós, no nosso corpo, o cosmo, a terra, a memória dos mortos e da beleza viva é o corolário do contraponto àquela linguagem instrumental dos vaqueiros nos diálogos anteriores a esse composto pelo texto e pelos discursos considerados aqui. 
Não se trata de propor, como tantos admiradores de Rosa e pesquisadores de sua obra fazem, que "Cara-de-Bronze" seria "poesia", "metapoesia" ou "registro poético" ou "prosa poética" ou que haveria, sobretudo em Cara-de-Bronze, "uma procura da poesia" $^{\prime \prime}$. Essas categorias genéricas nada esclarecem e criam uma neblina em que mesmo o burrinho da imagem não conseguiria farejar coisa alguma... O que os discursos dos vaqueiros José Adino, Cicica, José Uéua e Mainarte inauguram é um ponto de passagem, de deslocamento para o relato do Grivo, para um único centro de valores que gira em torno do que poderíamos nomear de poesia.

Entretanto, de uma perspectiva filosófica materialista e da perspectiva cultural e discursiva bakhtiniana, essa complexa questão não pode ser resumida pela palavra "poesia" simplesmente porque, no âmbito de qualquer análise discursiva literária (não só a dialógica), não se pode chegar a alguma conclusão sobre coisa alguma se não houver um questionamento sobre essa coisa, se ela não for pensada em conexão com o objeto (no caso, estético) de onde provém, se a ela não forem relacionadas outras variáveis valores, dimensão linguístico-discursiva, especificações culturais etc.

Sem dúvida, podemos considerar poéticos os discursos expressivos, analógicos, imagéticos e altamente sugestivos dos vaqueiros citados. Porém essa constatação, longe de ser um truísmo ou uma verdade inquestionável e naturalizada, traz-nos problemas sérios para reflexão. Em primeiro lugar, no texto de Rosa não encontramos apenas discursos poéticos. Há registros informais mais instrumentais propriamente ligados ao trabalho, à lida dos vaqueiros; há também o discurso do narrador materializado em variedade urbana, como é também o caso do personagem Moimeichêgo, além do registro informalestético do Cantador, permeando praticamente toda a narrativa. Isso além de registros de muitas variedades desprestigiadas que conformam as falas dos vaqueiros, estando eles na lida ou, em momentos de descanso, conversando entre si.

Em segundo lugar, discursos poéticos não são apenas "discursos poéticos", ou seja, registros capazes de nos silenciar maravilhados apenas como sequências sonorosemânticas expressivas que valem de per si. Um discurso poético - desde que não seja mera experiência formalista estéril - será sempre um discurso complexo, não porque vai "à essência do ser" ou do humano no homem ou outras considerações metafísicas ${ }^{6}$, mas

5 Em hipótese alguma contestamos a dimensão poética confirmada por quase todos os ensaístas e articulistas de muitas esferas do conhecimento humano (não só a literária) que se dedicam ao estudo da obra multifacetada de João Guimarães Rosa. Apenas nos referimos a ela com as categorias de análise que nos couberam segundo nossa orientação teórica e epistemológica.

6 Seria insensatez deslegitimar os estudos dedicados à obra rosiana a partir de um viés filosófico, metafísico, mítico ou mesmo arquetípico. Exemplo extraordinário disso são os vinte e seis artigos e cinco capítulos de 
- Os diálogos na construção de textos e discursos de "Cara-de-bronze", de João Guimarães Rosa: dimensão poética e centros de valor

porque é profundamente dialógico, ou seja, profundamente alterado, no sentido mesmo da alteridade. Porque se constitui a partir do outro e porque constitui o outro a partir de si.

Nos discursos do diálogo em análise do qual participam os vaqueiros Cicica, Adino, Mainarte e José Uéua - a partir de uma pergunta do forasteiro Moimeichêgo os dois últimos retomam a palavra monológica dos dois primeiros e não a desprezam: antes, dialogam com ela, dialogando entre si também e colocando nesse diálogo outra voz, só que em forma complexa de silêncio - a voz de Segisberto Saturnino Jéia Velho, Filho, o patrão, o Cara-de-Bronze, o Velho. As enunciações de Mainarte e de José Uéua são complexas não porque sejam poéticas, mas porque profundamente dialógicas.

A imaginação, produto essencial dos sentimentos, como consequência da alegria, produto da compreensão de diferenças semelhantes, ou seja, da compreensão (e não cooptação) do outro, das alteridades, segundo José Uéua e Mainarte, é matéria mesma dessa complexidade. Há complexidade porque há essas considerações nos discursos dos vaqueiros. A complexidade não pode ser um signo que paire nas nuvens (assim como a poesia): há de rastreá-lo na neblina de sua materialidade. Sem medo de me contradizer, posso dizer que o estilo de Mainarte e José Uéua é poético porque complexo e não o contrário. A complexidade, de maneira geral, exige recursos linguístico-discursivos que extrapolam a palavra sem nuance, monológica, definitiva, cartesiana, fechada em si mesma, recursos que abracem uma racionalidade imaginativa e um materialismo sensível, construídos em interações intersubjetivas que têm como elemento nuclear a alteridade, a voz do outro, ou seja, interações integralmente dialógicas.

Os discursos do primeiro diálogo vagueiam: andam ou passeiam sem rumo certo, ao acaso, tateando a complexidade dos sujeitos envolvidos nas interações, suas contradições, seu inacabamento constitutivo. Negam os caminhos retos, a linguagem monológica, a palavra definitiva, preferindo os caminhos mais tortuosos, sinuosos e as paragens mais amplas e mais complexas da alteridade e relações dialógicas. Esse primeiro diálogo é, nessa narrativa repleta de nuances, o primeiro índice do deslocamento dos discursos, em movimento centrípeto, para o relato do Grivo, com a convergência dos diversos centros de valor em jogo para um único, identificado com o que podemos chamar, sem muito rigor, de "poesia".

livros de Benedito Nunes dedicados à obra de João Guimarães Rosa dos quais destaco individualmente o estudo "O amor na obra de Guimarães Rosa", presente no já clássico $O$ dorso do tigre (1964). Também a título de exemplificação, como deixar de mencionar os muitos estudos críticos da ensaísta Suzi Frankl Sperber, além das inúmeras dissertações de mestrado e teses de doutorado que tiveram como tema alguma dimensão da obra rosiana, orientados por ela ao longo de sua carreira de professora e pesquisadora no Instituto de Estudos da Linguagem (IEL) da Universidade Estadual de Campinas (UNICAMP)? O que estamos dizendo e redizendo neste artigo é que nossa apreciação se filia à concepção dialógica do discurso (bakhtiniana) e os desdobramentos de nossas considerações obedecem naturalmente a essa filiação. 


\section{Textos-enunciados $\mathrm{n}^{\circ} 02$ e $\mathrm{n}^{\circ}$ 03. A viagem do grivo: a convergência das vozes}

O relato do Grivo se constitui como o diálogo (ou conjunto de diálogos) mais complexo de "Cara-de-Bronze". Começa com uma espécie de justificativa do narrador para a dificuldade da sua empreitada em relação aos vaqueiros: como relatar aos vaqueiros os acontecimentos, os acidentes geográficos, as notícias sobre os viventes com a mesma linguagem com a qual o teria feito ao Cara-de-Bronze? E sobre os conteúdos? Aqueles que seriam mais caros a Segisberto Jéia seriam repartidos com a vaqueirama? E as nuances etéreas, os fatos bizarros, a matéria ora clara ora opaca da memória e das percepções? E aquilo que pertenceria só a ele: Não sei. Eu quero a viagem dessa viagem... (ROSA, 2006, p. 143) e que não repartiria nem com o Cara-de-Bronze? Ora, a única coisa que sabemos daquele relato é que ele certamente teria sido feito em uma linguagem altamente simbólica e expressiva, pois essa parece ter sido a exigência primeira do patrão.

(1) - Eu vos conto, por miúdo. Desde daqui saí, do Urubuquaquá, conforme o comum - em direitura. Andei os dias naturais. Fui. Vim-me encostando para um chapadão feio enorme. Lá ninguém mora lá - só em beira de marimbú - só criminoso. Desertão, com uma lepra de relva. Dez dias, nos altos: lá não tem buriti... Água, nem para se lavar o corpo de um defunto...

(2) - Chapadão de Antônio Pereira?

(3) Virou dessas travessias.

(4) - Sempre nos Gerais?

(5) - Por sempre. O Gerais tem fim?

(6) Ao que são campinas e chapadas e chapadões e areiões e lindas veredas e esses escuros brejos marimbús - o mato cerrado na beira deles.

(7) - Subi serra, o sol por cima. Terras tristes, caminho maus...

(8) Mas beirou a catinga alta, caminhos de caatinga, semideiros. Sertão seco. No aperto da seca. Pedras e os bois que pastam na vala dos rios secos. Lagôas secas, como panos de presépio. Caatinga cheia de carrapatos. Lá é que mais esquenta. A caatinga da faveleira.

(9) - Acompanhei um gado, de longe, para poder me achar...

(10) Tornou esquerda, seus Gerais. Todo buriti é uma esperança. Achou os brejos, nos baixões.

(11) - Na chapada, as motucas não esbarravam de me ferroar: minha cara e minhas mãos empolaram inchadas, dum vermelho só... [...]

A primeira enunciação obviamente é do Grivo: ele conta algo a mais de um interlocutor (Eu vos conto) e os verbos estão colocados no pretérito perfeito: saí, fui, vim(me). De acordo com essa estrutura verbal, podemos afirmar que as enunciações do 
- Os diálogos na construção de textos e discursos de "Cara-de-bronze", de João Guimarães Rosa: dimensão poética e centros de valor

Grivo são as de números (1), (5), (7), (9) e (11). O travessão será o indicador de suas falas. Há, porém, enunciações que são marcadas por travessão e que não são do Grivo; elas correspondem às falas (2) e (4). Repare-se que à pergunta (2) não há uma resposta. A única resposta do Grivo é a de número (4) e, mesmo assim, ela traz, na sequência, uma pergunta (O Gerais tem fim?).

As ocorrências (7), (9) e (11) são enumerações dos lugares por onde ele passou e não respondem a nenhuma pergunta especificamente. O operador "mas" que inicia a enunciação (8) não é adversativo, pois não se contrapõe à enunciação (7) do Grivo, mas uma enumeração dos lugares por onde o Grivo andou (tendo, portanto, a mesma função que as enunciações (7), (9) e (11)). Essa voz que, além da enunciação (8), se faz presente nas de números (3), (6), (8) e (10), complementando as descrições que o Grivo faz de parte de sua viagem, não são do Grivo, pois não iniciadas por travessão.

De quem seria a voz que, introduzida por travessões, pergunta ao Grivo se ele passou pelo Chapadão de Antônio Pereira e indaga se ele foi ou não para além dos Gerais? E sobre a voz que se manifesta em quatro enunciações, completando as enumerações do Grivo sobre os lugares onde esteve? Não é possível atribuir as falas sem travessões como vozes dos vaqueiros, pois eles estavam ali para indagar do Grivo sobre a viagem e não para "ajudar" o Grivo a descrever lugares de uma viagem da qual não participaram. Por isso, as perguntas com travessões podem ser atribuídas a um vaqueiro (ou a dois deles) e as descrições complementares, ao narrador, chamado, por Santiago (2012, p. 53) de "fantasmagórico".

A tese de Santiago de um narrador anômalo pode encontrar eco nas partes do diálogo em que o narrador se encontra com as respostas do Grivo sem a participação dos vaqueiros, em um arranjo de vozes bastante estranho e perturbador. Faremos algumas observações sobre isso depois da reprodução do texto n. ${ }^{0} 03^{7}$, abaixo colocado.

(1) "O Grivo alguma vez parou, duvidou. Que-maneira hesitou?

- Tenho costume de tristeza: tristeza azul tarde, água assim. Tenho um medo de estar sem companheiro nenhum; não tenho medo desse mundo sendo triste tão grande...

(2) Estava só. E as árvores?

- As árvores são cabeças de vento...

7 O artifício da enumeração das enunciações dos participantes do diálogo se justifica para melhor localização das minhas considerações para os leitores. 
Alguma saudade?

- A saudade é braço-e-mão do coração, e que, certas horas, quer segurar demais em alguma pessoa ou coisa. Mas, não se deve-de...

(4) Ele era bobo?

- A vida é boba. Depois é ruim. Depois, cansa. Depois a vida não é de verdade... Sendo que é formosa!

(5) Não podia desistir?

- Ah, que não podia voltar pra trás, que não tem como. Por causa que quando o velho manda, ordena. Por causa que o Velho começa sempre é fazendo com a gente sociedade..."

Nos diálogos realizados entre os vaqueiros, de maneira geral, suas falas aparecem graficamente introduzidas por travessão ou pela identificação do vaqueiro ("O vaqueiro José Uéua", "O vaqueiro Tadeu" etc.). Na narração do Grivo, temos as contrapalavras e perguntas dos vaqueiros, devidamente introduzidas por travessão, mas encontramos perguntas e indagações que, aparentemente, parecem vir de lugar nenhum. Segundo Santiago (2012, p. 53), essas perguntas, feitas por esse narrador "fantasmagórico", são respondidas pelo Grivo como se ele as intuísse, como se as adivinhasse. Vamos às perguntas do narrador anômalo e as respostas do Grivo: a segunda pergunta (Estava só. Eas árvores?) bem como a terceira (Alguma saudade?) e a quinta (Não podia desistir?) colocam o Grivo como interlocutor, embora a segunda e a quinta possam ter como sujeito gramatical uma terceira pessoa: ele.

A terceira pergunta poderia pressupor a forma verbal tinha e, com isso, também a possibilidade do sujeito oculto ele, tudo isso trazendo uma forte perturbação ao (suposto) diálogo entre o narrador anômalo e o Grivo. Além disso, a quarta pergunta (Ele era bobo?) e a primeira (O Grivo alguma vez parou, duvidou. Que-maneira hesitou?) colocam o Grivo claramente como a terceira pessoa do discurso, acentuando ainda mais aquela perturbação e descaracterizando a possibilidade de diálogo.

As respostas são todas do Grivo (sua inserção nos diálogos são todas marcadas com travessão) em discurso direto, mas a última poderia ser interpretada como discurso indireto livre, ou seja, um discurso marcado por forte presença de alteridade (discurso do narrador e/ou do Grivo). A quarta pergunta (Ele era bobo?) mostra uma avaliação/ valoração forte desse estranho narrador que, além de não ter sido dirigida ao Grivo, pode ser interpretada como uma manifestação da construção arquitetônica da narrativa: como uma interferência de um centro de valor - o do autor-criador - que vai, aos poucos, se materializando e se impondo à narrativa à medida que os diálogos entre os vaqueiros vão convergindo para o relato do Grivo. 
- Os diálogos na construção de textos e discursos de "Cara-de-bronze", de João Guimarães Rosa: dimensão poética e centros de valor

É evidente que esse narrador anômalo está se referindo ao Grivo, fazendo uma crítica racionalista à linguagem expressiva e simbólica dele, mas ele não faria isso se referindo ao seu interlocutor em terceira pessoa, o que reforça a ideia de que o Grivo "intui" ou "adivinha" como se uma voz etérea soprasse nos seus ouvidos as perguntas para lhes oferecer, em seguida, uma contrapalavra. Santiago explica estruturalmente esse narrador anômalo através de algumas analogias que faz entre os "influxos modernizantes" e a cultura erudita/letrada e entre "os fundamentos do sistema latifundiário" e a(s) cultura(s) popular(es) e também seus polos opostos - sistema latifundiário/influxos modernizantes e cultura erudita/letrada e cultura(s) popular(es) presentes em "Cara-deBronze", evidenciando, através da estrutura formal de "Cara-de-Bronze", uma crise da representação. Para ele, "Guimarães Rosa transformou o caráter problemático do nosso processo de modernização num princípio estrutural levado às últimas consequências em 'Cara-de-Bronze'" (SANTIAGO, 2012, p. 57). A tese de Santiago está fundamentada em perspectiva materialista, não deixando de lado, como boa parte dos intérpretes e estudiosos de Rosa fazem, a dimensão histórico-social da obra.

Sem dúvida, as incursões formais na estrutura do texto como a definição, por parte do autor, de ladainha para o diálogo descritivo dos vaqueiros sobre os aspectos físicos do "Cara-de-Bronze" (ROSA, 2006, p. 103-106) ou ainda a roteirização cinematográfica com nomenclatura técnica - GPG (Grande Plano Geral), P.A (Plano Americano) e P.E.M (Plano de Enquadramento Médio) da preparação para a lida dos vaqueiros com o gado (ROSA), p. 108-112) trazem a cultura letrada para a obra, no caso do roteiro e também a cultura popular, no caso da ladainha, corroborando a sua tese do convívio paradoxal entre o moderno e o arcaico (razão maior para a suposta "crise de representação" instaurada pelo autor-criador) em "Cara-de-Bronze".

No entanto, gostaria de colocar a questão num campo mais dialógico, bakhtiniano, por assim dizer. Trazê-la para interior do próprio objeto estético criado por João Guimarães Rosa. Minha intenção é a de relativizar a tese de Santiago com algumas inquietações. Essa anomalia do narrador, a meu ver, faz parte da arquitetônica mesma dessa narrativa paradigmática que leva às últimas consequências seus limites formais, sejam eles linguísticos, discursivos ou ligados à ordem da representação .

Esse narrador é peça de uma engrenagem poderosa que faz com que os diálogos e os discursos dos vaqueiros, a princípio, com seus próprios centros de valor, sofram um

8 Não estou aqui me opondo à tese de Santiago, elaborada com fundamentação sólida no campo da sociologia e da história. Embora provindas de lugares epistemológicos distintos, não há discordância, mas complementaridade entre a minha tese e a dele. 
deslocamento e uma convergência para o relato do Grivo, ou seja, para um único centro de valor identificado com o que (já chamei a atenção para isso) podemos chamar de "poesia" ou, segundo alguns estudos sobre o Cara-de-Bronze, "uma procura da poesia". Vejamos: a homologia é flagrante. O leitor/interlocutor, aos poucos, através de um discurso que, embora relativizado por registros linguísticos outros, vê adensar-se o estilo poético da linguagem da narrativa, é levado até a poesia, assim como o Grivo saiu à procura da poesia.

Assim, baseado nestas observações, posso afirmar que esse narrador é de fato anômalo não em relação a uma crise de representação do texto literário, mas sim em relação à arquitetônica deste objeto estético. Para além de uma crise de representação (perfeitamente possível nas formas modernas e contemporâneas das narrativas), o que interessa a Bakhtin é a irredutibilidade do objeto estético a explicações e exegeses que não venham do próprio objeto estético, que venham de fora para dentro, como alguns procedimentos analíticos do marxismo ortodoxo. Por outro lado, não são todas as considerações de dentro para fora que mostram o objeto estético em sua inteireza, como, por exemplo, as considerações, no início do século XX, do formalismo russo a respeito da literatura e da poesia.

Não podemos nos esquecer de que aquela irredutibilidade do objeto estético é porosa, é permeável às dimensões éticas (o ato ético) e cognitivas (o conhecimento) da vida concreta, aos seus valores e contradições. Partindo, portanto, do meu ponto de vista, aquela voz ouvida por Santiago (2012) pode ser mais de uma voz (em sentido fortemente dialógico): ecoam neste estranho discurso, aparentemente exclusivo do narrador, a voz de um narrador, a voz do autor-criador e também a do Cara-de-Bronze, se entendermos a voz desse último como potencialidade. Todas devidamente singulares e, ao mesmo tempo, constituindo-se em uma única voz.

O que explica isso é a estrutura arquitetônica do texto de Guimarães Rosa, trabalhada, como já afirmamos, para o deslocamento e a convergência de diversos centros de valor para um único. $\mathrm{O}$ autor-criador, que soube distribuir os centros de valor entre os seus personagens vaqueiros, teve que reduzi-los a um único centro de valor; aquilo que era no início heterodiscurso se vê transformado gradativamente em uma narrativa monológica. Por sua vez, o narrador está colado ao autor-criador, fazendo de uma exotopia inicial plena, o colocar-se de fora que permite ao autor-criador criar seus personagens respeitando-se as alteridades, uma exotopia exígua, quase agônica, com a apologia idealista e metafísica do discurso poético.

O Cara-de-Bronze, outra voz situada na mesma frequência da do narrador, merece uma consideração à parte. Esse estranho personagem, que poucos vaqueiros conhecem 
- Os diálogos na construção de textos e discursos de "Cara-de-bronze", de João Guimarães Rosa: dimensão poética e centros de valor

e que, no final da vida, quis a ressignificação de sua memória através de enumerações poéticas do lugar onde viveu a infância e a juventude; esse personagem misterioso de quem se fala com espanto, medo e perplexidade, foi aquele que, se não pediu para o Grivo trazer-Ihe poesia, exigiu dele (ou descobriu nele) um discurso altamente sugestivo, simbólico, nuançado e expressivo, numa expressão: um discurso em estilo poético. Daí sua voz emanar também das enunciações do narrador. É a essa trindade, enfim, que é delegada a responsabilidade do deslocamento e convergência dos discursos que levam a narrativa para um único centro de valor.

O relato do Grivo é de segunda mão: ele, antes de ser dito para os vaqueiros, foi dito ao Cara-de-Bronze. Intuímos (pois não há registro explícito na narrativa desse diálogo entre o Grivo e Segisberto Jéia) que o relato ao Cara-de-Bronze correspondeu à necessidade do patrão de ouvi-lo de maneira poética. No entanto, diante dos vaqueiros, o Grivo não pode fazer uma paráfrase empobrecida do relato original feito ao patrão; ele não pode banalizar algo que, não negando o estilo poético de muitas das falas dos vaqueiros, está na esfera do mistério, do inefável, na esfera da poesia, agora, sim, considerada de um ponto de vista filosófico idealista.

Muitos dos estudiosos que escreveram sobre "Cara-de-Bronze" defendem a tese de que a novela de Rosa seria metapoesia ou que ela poderia ser resumida a uma "busca da poesia" (CINTRA, 1995; HILL, 2009, entre outros). Ao contrário, para mim não se trata de metapoesia e o Grivo não foi "em busca da poesia" e muito menos a trouxe para o Cara-de-Bronze. Não há metapoesia em "Cara-de-Bronze" porque para afirmar-se isso, dever-se-ia ter a integralidade de seus discursos em estilo poético, o que, como já vimos, não há. O que há é um diálogo de linguagens que envolvem registros poéticos e nãopoéticos, dialetos sociais e variedades não prestigiadas da língua. Em segundo lugar, esses discursos, mesmo quando expressos em estilo poético, não têm como tema a poesia, mas a viagem do Grivo. Por isso, não podem ser considerados metapoesia.

A única possibilidade de entendimento da novela de Rosa como poesia ou metapoesia seria a consideração do texto todo como uma grande metáfora, o que, de minha perspectiva, faria subsumir os discursos dos vaqueiros (e sua relação com a alteridade), a problemática do narrador e a exotopia e até o centro nevrálgico do texto de Rosa, a viagem do Grivo e o deslocamento e convergência dos centros de valor para um único centro de valor, ou seja, as variáveis mais interessantes para uma leitura dialógica de "Cara-de-Bronze". Deixando de lado essas variáveis, bastaria ao articulista apenas enumerar as passagens mais "poéticas" da narrativa como argumentos para sua tese. 
Mas o Grivo não foi em busca de poesia, pois, embora não saibamos exatamente o que o Cara-de-Bronze pediu a ele, com certeza ele não pediu ao sensível sertanejo que Ihe trouxesse poesia. É lógico que o escolhido para a viagem foi o Grivo justamente por causa de sua linguagem poética, mas isso não autoriza ninguém a acreditar que o patrão teria pedido como presente de viagem a "poesia". Minha certeza tem como base a história de Segisberto Saturnino Jéia Velho, Filho, contada em algumas passagens da novela. Tadeu se refere a ele, quando chegou à região, como "endividado de ambição, endoidecido de querer ir arriba [...]" e que

Arcou, respirou muito, mordeu no couro-crú, arrancou pedaços do chão com seus braços. Mas, primeiro, Deus deixou, e remarcou para ele toda sorte de ganho e acrescentes de dinheiro. Do jeito não teve tarde em fazer cabeça e vir a estado. Tinha de ser dono. Vocês sabem, sabem, sabem: ele era assim. (ROSA, 2006, p. 101).

O mesmo Tadeu lembra, em outra passagem, que o Cara-de-Bronze teve que fugir para lá, pois acreditava que tivesse matado o pai com um tiro, o que, muitos anos mais tarde, foi desmentido: o pai tinha caído, pois estava bêbado e não porque Segisberto o teria alvejado.

O narrador nos conta que, na ocasião em que o Velho conduziu o Grivo, Mainarte e José Uéua às imediações, "mandava-os por perto, a ver, ouvir e saber [...]. Até o cheiro de plantas e terras se espiritava. [...]" e por que Segisberto queria tudo isso? "Tirar a cabeça, nem que seja por uns momentos: tirar a cabeça, para fora do dôido rojão das coisas proveitosas [...]" é a resposta do narrador (ROSA, 2006, p. 122). Além disso, o mesmo narrador nos explica que "o Velho fez o Urubuquaquá, amontoou riquezas. Mas o que fazia, era para se esquecer de si, por desimaginar [...]" (ROSA, 2006, p. 115) e conclui dizendo que "o Cara-de-Bronze tinha uma gota-d'água dentro do seu coração. Achou que tinha. Pensou. Quis. Mas isso são coisas deduzidas, ou adivinhadas, que ele não cedeu confidência a ninguém" (ROSA, 2006, p. 116).

Apesar do despiste das coisas deduzidas, pois Segisberto não teria dito isso a ninguém, o que tem a evidente função de manter o mistério intocável dos diálogos privados no quarto entre o patrão e os três vaqueiros, há indicações fortes de que o Carade-Bronze, no crepúsculo de sua vida, teve necessidade de algo novo, algo que escapasse de seu poder, de seu dinheiro, dos bens acumulados para se esquecer de si, por desimaginar. E a possibilidade por excelência para isso era ouvir de outra maneira, através de outro tipo de linguagem, mais expressiva e sugestiva, menos direta e mais alusiva e, por isso mesmo, encantatória. Em uma palavra: poética. Como quem escutasse em outra língua sobre as coisas que nos são familiares. Consequências da "gota d'água dentro do seu coração?". 
- Os diálogos na construção de textos e discursos de "Cara-de-bronze", de João Guimarães Rosa: dimensão poética e centros de valor

Corro o risco de ser entendido como "mais realista que o rei", pois Guimarães Rosa, em mais de uma ocasião, afirmou que "Cara-de-Bronze" tratava da "procura da poesia". Isso está explicitamente em uma das cartas que trocou com seu tradutor do italiano, Edoardo Bizzarri. Diz-nos Rosa: “Assim como 'Uma Estória de Amor' tratava de estórias (ficção) e 'O Recado do Morro' trata de uma canção a fazer-se, 'Cara-de-Bronze' se refere à POESIA" [...]. A conclusão: "O Cara-de-Bronze, pois, mandou o Grivo... buscar poesia. Que tal?" (1981, p. 60). No entanto, Paulo Rónai é também citado na mesma carta em um resumo que faz da novela, afirmando que os elementos em enumeração que o Grivo traz "permitem reconstruir para seu próprio uso a realidade íntima do passado, uma visão poética de seu universo [...]" (1981, p. 59-60).

Ou seja, para o estudioso húngaro-brasileiro, o Grivo trouxe para o Cara-de-Bronze elementos para que Segisberto Saturnino reconstruísse sua memória antes de morrer, hipótese que se coaduna bem mais com a minha. Acredito, portanto, que a reconstrução da memória seja o motivo para que o Velho enviasse o Grivo para seus rincões amados, reconstrução que deveria ser narrada em registro poético.

\section{(Possível) conclusão}

Meu trabalho partiu da percepção de que os diálogos, em "Cara-de-Bronze", são elementos fundamentais na gênese dos textos e dos discursos nas interações verbais entre os vaqueiros, o narrador (algumas vezes, "anômalo"), os personagens forasteiros e o cantador que acompanha, com suas trovas, cada um dos textos e discursos que lhes dão forma. A partir daí, delimitei três textos-enunciados para uma reflexão que considerou como objetos privilegiados as relações dialógicas desses discursos e a dimensão poética da narrativa.

Esse discernimento adveio de duas constatações que fiz com minha leitura do texto: uma primeira, que se deu a partir de um dado central de sua arquitetônica: o deslocamento paulatino de seus textos, discursos e centros de valor para um único centro de valor, expresso por uma dimensão discursiva mais sugestiva, simbólica, expressiva, metafórica e nuançada, que culmina com o relato que faz o vaqueiro Grivo de sua viagem aos colegas vaqueiros. A segunda constatação me veio de parte da fortuna crítica de "Carade-Bronze": a percepção, por parte de pesquisadores e críticos, de que a novela de Rosa tem uma relação bastante forte com o que se chamou de "poesia", "discurso poético", "procura da poesia", "dimensão poética", "metapoesia", entre outras denominações.

Quis, então, a partir dessas constatações, propor uma discussão mais nuançada da dimensão poética do texto de Rosa, esforçando-me por não perder as relações dialógicas 
de textos e contextos e por fazer do fenômeno poético, sua linguagem, ressonâncias, estrutura e valores, algo terreno, palpável, material, inserido na linguagem de homens e mulheres em determinada cultura e sociedade e determinado momento histórico. Tentativa de resgate da poesia das nuvens em que sempre foi colocada seja pelo senso comum, seja por uma apreciação idealista de estudiosos, que a colocam como algo inalcançável, sublime, superior; portanto, elitista.

Quando o vaqueiro Maçapira coloca mais lenha na fogueira e assopra, alumiando, com as chamas, as caras dos vaqueiros, agora vermelhas (ROSA, 2016), começa a finalização e o ápice do relato do Grivo. A resposta do Grivo à pergunta de Cicica sobre o que teria trazido da viagem - Ninguém não enxerga um palmo atrás do seu nariz... - só reforça a guinada da estória para o campo do entendimento poético: o que estaria atrás dos narizes? O interior do homem? O hemisfério direito do cérebro, responsável pela intuição, pela sensibilidade, pelo "terceiro" sentido? A própria poesia?

A poética do relato, neste momento, torna-se mais densa: O Grivo lembra uma pergunta do Velho: "Como é rede de moça - que moça nôiva recebe, quando se casa?", respondida por ele da seguinte maneira: "É uma rede grande, branca, com varandas de labirinto..." e completada por Mainarte: "Jogou a rede que não tem fios". O Grivo retoma: "Eu quero a viagem dessa viagem...".

O que está sendo sugerido aqui através das forças que operam a transformação de centros de valor diversos em um único centro de valor, que gira em torno da poesia, é que só o discurso encantatório da poesia pode reunir os contrários, pacificar as vontades, expandir o mundo humano para além dos seus limites e resolver os conflitos.

Não é por acaso que a necessidade de relatos poéticos parte, contraditoriamente, de um homem rude, voltado ao poder e de todo avesso à sensibilidade e - em uma palavra - à própria poesia. Volta-se, portanto, à palavra primeira, à palavra primeva, ancestral. Volta-se à ideia de que, ao contrário do que nos diz a filosofia na história moderna do Ocidente, foi a poesia que criou a linguagem e não o contrário.

Para Bakhtin, o autor-criador é o princípio organizador da obra de arte. Essa é sua responsabilidade, sua respondibilidade no ato ético da criação. Mas, também segundo Bakhtin, cabe aos estudiosos de uma determinada obra, complementá-la e ampliála com seus comentários críticos, enlaçando-a assim a uma rede dialógica de muitas outras vozes, que só a enriquecem no passar dos anos no "grande tempo". Essa, a minha responsabilidade. A nossa. 
- Os diálogos na construção de textos e discursos de "Cara-de-bronze", de João Guimarães Rosa: dimensão poética e centros de valor

\section{REFERÊNCIAS}

BAKHTIN, M. O texto na linguística, na filologia e em outras ciências humanas. In:

BAKHTIN, M. Os gêneros do discurso. Tradução Paulo Bezerra. São Paulo: editora 34, 2016. p. 71-107.

BAKHTIN, M. Questões de literatura e de estética (a teoria do romance). Tradução Aurora Fornoni Bernardino et al. São Paulo: Hucitec/Editora da UNESP, 1993.

BRAIT, B. Perspectiva dialógica. In: BRAIT, B.; SOUZA-E-SILVA, M. C. Texto ou discurso? São Paulo: Contexto, 2012. p. 9-29.

CINTRA, E. C. A viagem de Moimeichêgo - Um estudo da metapoesia em Cara-deBronze. Itinerários, n. 8, p. 67-76, 1995.

FARACO, C. A. Linguagem \& diálogo. As ideias linguísticas do Círculo de Bakhtin. São Paulo: Parábola, 2017.

HILL, A. G. Cara-de-Bronze. Navegações, Rio de Janeiro, v. 2, n. 2, p. 91-94, jul./dez. 2009.

HOLANDA, S. A crítica de Guimarães Rosa. Revista Cult (blog UOL). Disponível em: revistacult.uol.com.br/home/critica-de-guimarães-rosa. Acesso em: 02 out. 2020.

NUNES, B. O amor na obra de Guimarães Rosa. In: COUTINHO, E. F. Guimarães Rosa. Rio de Janeiro: Civilização Brasileira, 1983. p. 144-169.

ROSA, J. G. Cara-de-Bronze. In: ROSA, J. G. No Urubuquaquá, no Pinhém. Rio de Janeiro: Nova Fronteira, 2016. p. 89-144.

ROSA, J. G. Correspondência com seu tradutor italiano Edoardo Bizzarri. São Paulo: T.A Queiroz, Editor, 1981.

SANTIAGO, E. Como burro no arenoso. As contradições da forma em "Cara-de-Bronze" de Guimarães Rosa. Revista Magma, São Paulo, n. 10, p. 50-57, 2012. 
COMO CITAR ESTE ARTIGO: GOMES, MARQUES, José Geraldo. Os diálogos na construção de textos e discursos de "Cara-de-bronze", de João Guimarães rosa: dimensão poética e centros de valor. Revista do GEL, v. 17, n. 3, p. 143-163, 2020. Disponível em: https://revistadogel.gel.org.br/

DOI: http://dx.doi.org/10.21165/gel.v17i3.2866

Submetido em: 26/07/2020 | Aceito em: 22/10/2020. 